\title{
LA LITERATURA Y SU 'RECONCILIACIÓN' CON EL LECTOR EN LA ERA TECNOLÓGICA Gilberto Castrejón*
}

\begin{abstract}
RESUMEN: Actualmente, la literatura ha asistido a una especie de reapropiación de sus espacios, intereses y alcances; al ser desplazada como expresión artística por antonomasia frente a diversos medios o formas de expresión y comunicación propios de nuestra época, suscita poca efervescencia en los lectores potenciales. El artículo desarrolla un conjunto de reflexiones sobre ciertas posibles fórmulas que el escritor ha de sortear para 'reconciliarse' con el lector y atraer su atención en la era tecnológica, donde la cultura es más visual y cada vez menos escrita.
\end{abstract}

PALABRAS CLAVE: Literatura, escritor, lector, era tecnológica.

RECEPCIÓN: 30 de julio de 2008.

ACEPTACIÓN: 24 de septiembre de 2008.
ABSTRACT: Currently, literature is going through a stage of reappropiation of its spaces, interests, and scope: being replaced by various forms of expression and communication as the ideal means of artistic expression nowadays provokes little enthusiasm in potential readers. This article sets forth various ideas regarding possible ways that writers could employ in order to reconnect with readers and draw their attention in the technological era where culture is increasingly more visual and less written.

KEYWORDS: Literature, writer, reader, technological era.

* Unidad Profesional Interdisciplinaria en Ingeniería y Tecnologías Avanzadas, Departamento de Ciencias Básicas, Instituto Politécnico Nacional. 


\section{LA LITERATURA Y SU 'RECONCILIACIÓN' CON EL LECTOR EN LA ERA TECNOLÓGICA}

La literatura es como el fósforo: brilla más en el instante en que intenta morir.

Roland Barthes. El grado cero de la escritura.

To oda crisis ha de inaugurar un estado distinto del ya existente.

Comencemos por preguntarnos si efectivamente la literatura está en crisis, de aquí que una respuesta afirmativa podría esperarse de un literato y/o académico - para quien la forma y la creatividad se han ido parasitando-, no así, quizá, la del verdadero artífice de dicho arte: el escritor, para el cual precisamente existe una crisis de lectores, las editoriales no son las suficientes o remiten su atención sólo a cierto tipo de literatura, aunado al hecho de que ahora ya no existe un real y efectivo culto al libro, objeto y fin 'tangencial' de la escritura, pues "si el libro es siempre símbolo, la irreverencia hacia él resulta igualmente simbólica". ${ }^{1}$ Así, las respuestas y cuestionamientos se multiplican en razón misma del contexto histórico y de quién los exprese, pero el asunto es más complejo de lo que parece.

Ahora el estado de la cultura es distinto, las reglas del juego son otras y esto afecta directamente a la ciencia, el arte, la literatura, la política... Estamos colocados sobre infinitas redes de información, asistimos al fin de la modernidad a través de una crisis, ${ }^{2}$ pues se debe

${ }^{1}$ Julio Cortázar, Obra crítica 1, 1994, México, Alfaguara, p. 46.

2 Para algunos, la crisis de la modernidad está representada en lo trunco del proyecto, en la imposibilidad de llevarse a cabo; para otros, simplemente es aceptar que se ha dado paso a otro proyecto, que la posmodernidad es ya inherente a nuestra condición histórica. 
ir más allá del progreso, donde a su vez se asiste al declive de los mitos $\mathrm{y}$ donde hace falta un criterio que legitime las estrechas relaciones entre todas esas dimensiones que, digámoslo abiertamente, forman parte del mismo juego, que es el de poderes, el de los alcances propios de un discurso bien legitimado; ${ }^{3}$ dicho todo esto: "El criterio de operatividad es tecnológico." ${ }^{4}$ Y la literatura no es la excepción: adoptó al método en su seno, 'método de invención artístico' que nos viene desde el siglo XIX y que liberó al artista del apego a la representación, permitiéndole realizar libremente su arte, por ello se 'inventa', se explota un método, en pos de una supuesta originalidad. Así, en nuestra época es bien sabido que: "si la enajenación es una característica de la sociedad tecnológica, también es un síntoma el alejamiento, que los estetas suponían necesario para el arte". ${ }^{5} \mathrm{Y}$ en la literatura: todo lenguaje es historia, $\mathrm{y}$ una determinada posición frente a ésta, quizá el escritor siempre ha 'padecido' el alejamiento, pero: ¿estará, también él, enajenado?

${ }^{3}$ Me refiero aquí a todo ese conglomerado de discursos que pretenden dar cuenta del hombre moderno.

${ }^{4}$ Jean-François Lyotard, La condición posmoderna, 1998, Madrid, Cátedra, trad. Mariano Antolín Rato, p. 11.

${ }^{5}$ Wylie Sypher, Literatura y tecnología, 1977, México, FCE, trad. Mercedes Arnal Arnal, p. 14.
Desde hace algún tiempo, hemos terminado por aceptar que 'el orden de los discursos' posee también un carácter incitativo, ya no sólo se comunica o expresa, también se señala. Literariamente Burroughs lo ejemplifica con una sola frase: "Vi a Dios en mi ano durante el relámpago de la lámpara del flash del orgasmo." 6 La trasgresión está presente en estas pocas palabras: se vincula a Dios con el sexo, toda la frase es eminentemente homosexual, se habla de una parte erógena un tanto incómoda: el ano; pero finalmente, y he aquí un signo de los tiempos, se introduce, como dijera Mailer, 'un feo matiz tecnológico'. ¿Dónde está ese lenguaje pulcro y a veces burgués, digno de la época victoriana? ¿O tal vez el desapego a ciertas estructuras clásicas convierten a estas palabras en sólo una forma gramatical sin ninguna sustancia estética, dado su carácter transgresor? Lo importante es que señalan algo, tanto metafórica como contextualmente, y el contexto corresponde a la primera mitad del siglo $\mathrm{XX}$, donde la literatura, $\mathrm{y}$ en especial la narrativa, urgían de una reapropiación de sus espacios frente a las tendencias que la supuesta posmodernidad artística instauró y ha instaurado en el individuo.

${ }^{6}$ William S. Burroughs, El almuerzo desnudo, 2001, Barcelona, Anagrama, trad. Martín Lendínez y Francesc Roca, prólogo. 
Burroughs y muchos otros hicieron un disparo que habría de prolongarse hasta la actualidad, en cuanto a cierto carácter que habría de adquirir la literatura si desea seguir manteniendo lectores potenciales, siendo éstos últimos verdaderos hijos de su tiempo, ya que ahora el oficio de escribir ha de moverse por senderos no antes explorados, y donde la historia, la época, influye en el escritor, pues: "no pudiendo ofrecerle un lenguaje libremente consumido, la historia le propone la exigencia de un lenguaje libremente producido." ${ }^{7}$ La historia dice primeramente en qué punto del devenir estoy colocado, y bajo qué condiciones me debo de desenvolver, por ello: ¿es factible seguir cosechando las viejas fórmulas?

Llegados ya a este punto, ¿qué ha de hacer el escritor, en especial el que se dedica a la narrativa, para 'reconciliarse' con el lector, y atraer su atención en la era tecnológica, donde éste ha vertido su mirada en tecnologías y espacios de entretenimiento superficiales, en psicologías globalizadoras o juegos de video?

Distingamos primeramente ciertos hechos de esa urgencia por la reconciliación. El libro ya ni siquiera corresponde a 'esa esencia última del espíritu' como dijera Cortázar, no es

${ }^{7}$ Roland Barthes, El grado cero de la escritura, 1999, México, Siglo XXI editores, trad. Nicolás Rosa, p. 24. un fetichismo material, a la usanza del Club Dumas, de Pérez-Reverte, pues existe una especie de 'desprecio al libro', convirtiéndose éste en un artículo elitista, sólo para unos cuantos iniciados, no para la gran masa; asimismo, se instaura una concepción del libro con una engañosa fórmula: es un artículo de consumo, nunca básico, y ni siquiera responsable del acontecer cotidiano; está más lejos de la realidad que un disco compacto -a pesar de que ya puede adquirirse en esta presentación-, pero es algo decorativo y que da noción de clase, claro, esa noción de clase que distingue a unos de otros, pero sólo en un sentido meramente material, y centrados en esto es preciso decir que en cierta forma el libro no es accesible a todos. Y eso no es todo, indaguemos un poco en la naturaleza y condición del ser a quien está dirigida una obra literaria en su sentido más lato.

No es difícil entender que actualmente nuestros códigos de comunicación son más visuales, ya que ésta se ha trasladado del contexto sustancial de la palabra escrita al contexto visual; la mayoría de nosotros pasa un mayor tiempo frente a una pantalla que frente a un texto escrito; de este modo, cualquier persona cuenta con un número suficiente de imágenes listas para ser referidas en el momento preciso, las imágenes e intereses que pueden despertar los libros se desvanecen frente a las que 
la televisión o la multimedia nos proporcionan, y entonces se sufre una especie de 'mutación espiritual' de intereses, adquiriendo a su vez una 'razón instrumental', ${ }^{8}$ un modo característico de actuar y entender el mundo, y así, se es hijo fiel de la época, el tiempo de la cultura del ahorro, de la eficiencia, del consumo. "El mensaje con el cual la nueva cultura se recomienda y se autoelogia es que la cultura del libro es de unos pocos - es elitista-, mientras que la cultura audio-visual es de la mayoría."9 Porque en la actualidad pocos saben algo y muchos no saben nada, pero éstos últimos están informados, aunque esa información sirva de muy poco.

¿Cuáles son los senderos que el escritor debe granjear, para 'costearse' un cúmulo aceptable de lectores potenciales? Quizá una mirada a las características efectivas de los clásicos, dígase, como menciona Kundera, la multiplicidad de mundos contenida en las novelas europeas: El Quijote, Jacques el fatalista, Ana Karenina, etc., pues "las primeras

\footnotetext{
${ }^{8}$ Max Weber fue el primero en llamar la atención sobre las nuevas formas de racionalización de la modernidad, donde una especie de 'razón práctica' propia de dicho contexto histórico se hace presente, en el sentido de que cierta coherencia en la forma de valorar, actuar, elegir, simbolizar, etc., se le impone al individuo, debido principalmente al 'desencanto' por la religión, y a la influencia de la ciencia y la tecnología.

${ }^{9}$ Giovanni Sartori, Homo videns, 2001, México, Taurus, trad. Ana Díaz Soler, p. 40.
}

novelas europeas son viajes por el mundo, que parece ilimitado". ${ }^{10}$ El diario de la propia conciencia del lector. Con todo esto la literatura del siglo XXI debe hacer que el lector se reconozca en la obra, como una red universal conectada con todas las realidades. ${ }^{11}$ No por nada una obra como El hombre sin atributos contiene, además de todo, conocimiento, es extensa, cierto, pero eso no importa, toda una vasta gama de mundos se abre al lector. El narrador debe saber enfocar un juego preciso de espejos, en pos del 'lector cómplice'. Los temas pasan a segundo término, nada de tomar como estandarte los temas y estructuras clásicos, de la novela rosa, de caballerías, aventuras, costumbrista, revolucionaria, de la onda, realista..., el grito de batalla es otro: transparencia, efectividad, entretenimiento, levedad, exactitud. Italo Calvino ha mostrado con creces lo efectivo de estos atributos en su obra Seis propuestas para el próximo milenio, donde menciona que precisamente la literatura, con su muy particular y extraordinario carácter, puede, sólo ella, brindar una verdadera alternati-

${ }^{10}$ Milan Kundera, El arte de la novela, 1992, México, Vuelta, trad. Fernando de Valenzuela y María Victoria Villaverde, p. 15.

${ }^{11}$ En este sentido no hablamos precisamente de un carácter 'globalizado' de las historias, se puede atender a localismos, pero presentados de cierta forma que le sea suficientemente atractiva al lector. 
va al lector, ofreciéndole esa infinita red de posibilidades en las que su mundo globalizado y tecnológico actual lo sitúa, pues qué más sino "la literatura como función existencial, la búsqueda de la levedad como reacción al peso de vivir". ${ }^{12}$ Levedad incluso con los temas más profundos de la cartografía humana, lo que permite a Julian Barnes tratar un tema como el amor en Hablando del asunto, desde una premisa trillada: un triángulo amoroso, pero con una forma atractiva y asequible a cualquier lector, y donde el estilo es la estructura. Así, otra virtud a que alude Calvino es la rapidez, si el hombre posmoderno vive al día, sumido en una especie de metástasis comunicativa, el juego de espejos debe brindarle el mismo carácter que su avidez espera: le informa de cierta situación del acontecer, creando un efecto en él, que debe ser exactamente el buscado, logrando por ende otra de las virtudes que el escritor italiano resalta: la exactitud. De esta manera: todo debe ir conectado certeramente, ninguna palabra de más, ninguna de menos, la escritura barroca es un arma blanca, y por ello denota ambigüedades, la literatura no debe dejar nada a la deriva, ha de ser directa, ganar por knock out desde el primer asalto. La extensión es secundaria si

${ }^{12}$ Italo Calvino, Seis propuestas para el próximo milenio, 2001, Madrid, Siruela, trad. Aurora Bernárdez y César Palma, p. 41. atrapa desde el principio, pues toda obra que es consistente de manera global, ha de serlo en cada una de sus partes, enigma recurrente de todo principio holístico.

El siglo XX representó un verdadero parteaguas y 'reacomodo' para muchas disciplinas y artes, entre éstas la literatura; sin embargo, en este siglo surgieron también nuevas tendencias que aportaron un sin fin de perspectivas a lo ya aceptado por el establishment, y no sólo éste. Alguna vez un maestro de narrativa decía que novela es sinónimo de libertad, me atrevería a afirmar que la literatura debe deshacerse de ciertas cadenas tradicionales que la atan al pasado y parasitan su presente, no ya su, a veces, incierto futuro; la era tecnológica en la que estamos colocados nos ha hecho olvidar una de nuestras tareas esenciales como seres humanos: el cultivo del espíritu, aun desde su aspecto más bizarro. El escritor ha de ser un perfecto transgresor, enfrentarse a 'la criatura literaria' con un as escondido, ser un artesano que maneja la técnica, que posee vocación de río fluyendo ininterrumpidamente, si "del mismo modo, el matador que parece arriesgar el todo por el todo cuida su línea y confía, para triunfar sobre el peligro, en su sagacidad técnica", ${ }^{13}$ así,

${ }^{13}$ Michel Leiris, La literatura considerada como una tauromaquia, 1975, Barcelona, Tusquets, trad. Ana María Moix, p. 15. 
el que escribe ha de ser un matador, debe brindar una faena sublime, eliminar de su conciencia el hecho de que diversos medios o circunstancias le llevan un trecho de distancia, y que por ello ha perdido a sus lectores; si las formas tradicionales o clásicas de hacer literatura ya no causan interés en el lector, ni hacen que se involucre en la obra, pues a veces se presenta con un lenguaje sin ningún atisbo de numinosidad, preciso incluso apostar por fórmulas y géneros no muy nuevos, pero bastante efectivos. La ciencia-ficción, la fantasía y el terror ya están haciendo lo suyo con creces. Lo importante es escribir creando incendios, y hacer que los lectores lean, pues, parafraseando a Harold Bloom: ¿Para qué leer?, para que las personas tengan ideas propias, sientan y comprendan el mundo como seres libres. ${ }^{14}$

La crisis ya inauguró un nuevo estado, el de una literatura sin tabúes, con nuevos enigmas a resolver, con una efervescencia por 'asesinar' el lenguaje, y donde quizá 'el escritor es el enemigo potencial -y hoy ya actual-del idioma." 15

${ }^{14}$ Cfr., Harold Bloom, Cómo leer y por qué, 2000, Barcelona, Editorial Anagrama, trad. Marcelo Cohen, prólogo.

${ }^{15}$ Julio Cortázar, op. cit., p. 74. 
CITAM Derechos Reservados.

La reproducción total o parcial de este artículo se podrá hacer si el ITAM otorga la autorización previamente por escrito. 